\section{Gereral âdemarks}

ON THE

\section{PRACTICE OF MEDICINE.}

nY

P. M. LATHAM, M.D.

$$
\text { V.-CURE. }
$$

New Special Remedies : to be rigidly tested before their. Trustworthiness is admitted. Example of M. Louis. Such Remedies, long used and trusted, and at length proved worthless, are discreditable to the Common Sense of Physicians, and denote their faulty Education.

How far we are called upon to employ remedies which come to us from time to time with the repute of a special power to cure certain diseases, is an important and difficult question. I say emphatically, remedies to cure. New remedies to act upon this or that particular organ and its functions-new anodynes and sedatives, new diuretics, diaphoretics, or purgatives-are put to quick and easy proof, and the commonest observation cannot well err therein. They need only be given to a few different patients, and the question is soon settled whether they have or have not the virtues ascribed to them. Besides, we can easily understand how there may be substances unknown, or little known, or unaccountably neglected by the profession at large, which, being put to the proof, may turn out to have a power over certain organs of our body and their functions. These may be at length taken up by particular phy:sicians, who, from practice, learn to use them skilfully; and in their hands they are made to serve the purposes of procuring sleep, or assuaging pain, or raising or depressing the pulse, better than the remedies ordinarily in use for such purposes.

Indeed, any new remedy of this sort is well worth knowing and trying; for it may help us in the successful treatment of twenty different diseases. But the remedy which can achieve the summary cure of the single disease is the thing with which we are now concerned.

Now, an uncomfortable sort of suspicion possesses me that physicians from time immemorial have prescribed, and still go on prescribing remedies, upon the credit they have got of curing particular diseases, without the least reasonable evidence that the remedies ever did anything of the sort. The improved education of which we boast in our day ought to have made us less easy recipients of traditional errors, and more cautious in fabricating new ones of our own, and handing them on as evil gifts to our posterity. But it is not so.

When I was physician to a large hospital, having then the opportunity, it seemed almost a duty incumbent on me to gain an independent experience of sundry remedies which were much employed, with various degrees of credulity or faith in their curative powers. Indeed, I tried to do so; but (doubtless, from some fault of my own) I did not get on well with my task. Perhaps I was unduly sceptical, or not patient enough; or perhaps I was both. For men do not go to work with the same good will to detect what they suspect will turn out an error, as to confirm what they hope to find a truth. Moreover, in medicine (what men are scarcely aware of until they become somewhat severely practical), it requires as much labour and time fairly to lay hold of an error, and uproot it, and have done with it, as to learn and settle a truth, and abide by it. It is commonly to (what are called) chronic diseases that remedies said to cure have their application; each case spreading itself over a long time, is a case of mixed evidence; and, though a simple matter of fact is at issue, that evidence must be equally gone into, on whichever side the verdict may be in the end. Hence nothing is more certain than that numerous articles still encumber our materia medica, and still pass for being able to do something or other extraordinary, simply on account of the infinite time and trouble that would be needed to prove them utterly worthless.

When remedies claiming, however falsely, a special curative power, have been long in use, it is almost impossible ever to get rid of them. Their use then becomes a good deal like what the game of shuttlecock would be played by a crowd. The shuttlecock need never fall to the ground; there are so many to knock it about and keep it up. But, on such terms, it is a stupid game, or rather no game at all, and any left-handed clown can play at it.

Now it is only upon their first introduction into practice that special remedies are to be impartially examined and dealt with. In their trial, physicians of hospitals collectively have it in their power to become to some extent the safeguards of the profession ; and even individual physicians might do something to help us. Those especially who have bestowed much time and thought upon the investigation of particular diseases, whatever positive truths they may fortunately discover or explain, should consider their task still unfinished until they have pointed out the stumbling-blocks of false facts, false opinions, and false remedies; and made a clean sweep of them all. Strong in our esteem for the truths they have taught us, they would have equal authority in exposing error. But then they must not do it magisterially. They must admit us into their confidence, and make us sharers in their modes of proceeding.

There is a living physician who has made his profession doubly his debtors ; for not only upon whatever subject he has written has he imparted to us new knowledge, but, what is better even than new knowledge, he has by his manner of dealing with it given us, moreover, a constant pattern to follow, whereby each of us may pursue his own subject safely and successfully. This physician is M. Louis. Now that disease which is preeminently the scourge and terror of mankind has been to M. Louis the chosen subject of thought and of research during half his life, even pulmonary consumption. And when, for this pulmonary consumption, he comes to take account of all that in his experience art can do, he is constrained to admit that its resources are limited to the one sphere of treatment. The sum of his own experience is in treating, not in curing it. Nevertheless, he deems his work incomplete until he has reviewed the professed experience and success of others in the way of cure. Thus, with a patience and impartiality worthy of all praise, he passes in review ten different substances which, under th $\mathrm{e}$ shelter of good names and of seeming matters of 
fact, had gained the credit of a special power for the cure of phthisis.

The ten substances are-1, protioduret of iron ; 2 , chloride of sodium ; 3 , carbonate of potash ; 4 , sal ammoniac ; 5 , chloride of lime ; 6 , chlorine gas ; 7 , digitalis ; 8 , hydrocyanic acid; 9 , creasote $; 10$, iodine. Of hydrocyanic acid, creasote, and iodine, he considers it only necessary to remark the utter insufficiency of the evidence by which they come recommended to us as having power to cure consumption, and then leares them without a trial. Of chloride of sodium, induced by his respect for M. Latour, who had introduced it and emphatically recommended it, he made large trial. He gave it to every phthisical patient admitted under his care into the Hotel Dieu for five months successively; and in all that time he did not observe any change or amelioration in their condition which could be fairly accredited to the remedy. He saw nothing, in short, which is not constantly seen in phthisical patients placed under the same circumstances, and submitted to different treatment. He complains of the scanty and insufficient details in M. Latour's cases brought forward to recommend the remedy. Of carbonate of potash, recommended by M. Pascal of Strasburg with such poverty of detail as to leave it uncertain for what disease it was really given, though professed to be given for phthisis, he fairly excuses himself from making any trial. Of sal ammoniac or hydrochlorate of ammonia, recommended by $M$. Cless of Stuttgard, and of chloride of lime by Dr. Hirzoy of Posen, as curative agents in phthisis, he points to the brevity with which their cases are related to be such that they could hardly expect either to be believed or followed. Three substances remain, upon which he dwells at considerable length. These are protioduret of iron, digitalis, and chlorine gas. The care and patience and earnestness with which M. Louis betakes himself to treat of the first of these, the protioduret of iron, are remarkable. $\mathrm{He}$ starts with an evident desire and expectation of a favourable result ; for he knew and highly regarded MI. Dupasquier of Lyons, who introduced it into practice, and had employed it with much reputed success for several years. Having first taken care to make sure of the purity of the remedy, M. Louis administered it to upwards of sixty patients labouring under phthisis in all its stages, and in no single case did he observe any improvement which could be ascribed to the new agent. He cannot refrain from confessing his honest surprisc and disappointment that, after the fairest trial, it should have utterly failed in his hands. Of digitalis, it appears that M. Bayle had reasoned himself into the belief in it as a cure for phthisis-not that he had reached it by experiment. He had collected the evidence of twelve eminent physicians, resulting in the conclusion that, of a hundred and fifty-one cases treated by digitalis, eighty-three recovered, thirty-five experienced benetit permanent or temporary, and thirty-five no benefit at all. And this conclusion (or something near it) $M$. Bayle thought himself in all reason bound to accept, upon a choice of alternatives ; namely, to believe that eighty-three cases (or thereabout) of phthisis out of a hundred and fifty-one were cured by digitalis, rather than believe that twelve men of reputation and honour were mistaken in their diagnosis of the disease. But all these eminent authorities seem to have lived prior to the use of aus- cultation; and it is no disparagement either of their honesty or their skill to believe them quite mistaken, since they did not possess the means of a sure diagnosis. This is M. Louis' view of the question, and he does not think it necessary to make experiments purposely to settle it. During a dozen years he had prescribed digitalis to a few patients from time to time, without any positive result ; and the occasional trials of others had been alike unsatisfactory. To make the heart beat slower by digitalis, and so believe oneself remedying consumption, is about as wise as it would be to think of improving the weather by playing tricks with the barometer, or altering the real time of day by tampering with the clock.

Chlorine gas, administered by inhalation, once gained much repute for the cure of consumption; and M. Louis takes certain cases, twelve in number, brcught forward by $M$. Cottereau, as the most interesting within his reach, and makes careful examination of them one by one. To these examinations I would invite attention, as specimens of what is rarely met with in medical literature, and of what in the present state of our knowledge could be brought to bear on no organ of our body except the lungs. Each of them is a study in itself. It makes exact and discriminative analysis, by auscultatory signs and general symptoms, of consumption and of other diseases, as pneumonia and pleurisy, actually coexisting together during life; of their unequal rates of progress, and of the different effects wrought upon each by the impression of medicines, and the cessation and disappearance of the one while the other remains in its chronic state. Thus the conclusion results, that many of the cases in question were a complex of pneumonia or pleurisy and a certain amount of tubercles : the acute and remediable part, pneumonia or pleurisy, being remedied, left the patients in a satisfactory state for the present; while the few tubercles or incurable part still remained : further, that a few of the cases were simple unmixed pneumonia.

The analysis of each of these cases, so clear, so discriminate and exact, I have recommended as a study. But it will be a study not alike profitable to all, but to those only who are already accurately instructed and well exercised in diseases of the lungs, and, moreover, who have love and jealousy enough of the truths of practical medicine to think great pains well bestowed in disentangling them from constantiy besetting errors. Verily, there is nothing so selfdeceiving and evasive, and upon the whole so mischievous, as this love of specific remedies. It is akin to the love of the marvellous. If it get strong hold of a man, it incapacitates him from becoming a good physician. And why this continual search after a specific remedy for consumption?

If I were to name any single disease in which medicine has preeminent claims upon the gratitude of mankind for the largeness and certainty of the benefits received at its hands, I should name pulmonary consumption. True, I may believe pulmonary consumption to be incurable in the sense of having no remedy which can be brought to bear with counteractive effect upon its own nature; and I may greatly fear it to be incurable, in the more popular sense, that once begun it can never be brought to cease, and so entirely to disappear as if it had never been. But still, by patient study of its pathology and of what 
it is in its own nature, by patient scrutiny of what it shews itself to be in individual living men; of its seat and its extent, whether small or large, and its several stages; now, of its oneness and simplicity, and now, of its mixtures and complicutions; of its rates of progress, whether rapid or slow; and what it gives to the vital being of those whom it befals, and what it takes from it ; upon these several foundations we raise our great landmarks of the treatment of this disease. And thus, it has come to pass, that of the things in nature capable of acting upon man's body for good, every one, in its turn, has its just claim to be reckoned among the remedies of consumption in the way of treatmeint, but not one to be reckoned a remedy of consumption in the way of cure. Therc are a hundred remedies for consumption, but no single remedy.

The result of these investigations of $M$. Louis is to raise the curtain and to make us see an unwelcome truth where we would inuch rather not have found it. It puts in a very strong light the fact that the origin and spread of these lying wonders, and the mischicfs they carry with them, must be largely ascribed to physicians themselves.

This is a serious matter. Yet it would be well to look it in the face, could we only make sure of doing so honestly and without offence.

T'o insure success to those who practise it, modicine does not require that their understanding should be of the highest order, but it does require that it should be sound. Of all human pursuits, medicine suffers the greatest detriment from a small intellectual flaw. Not that practical medicine does not present work fit to engage the highest understanding; not that it does not even require the highest to carry it to its greatest perfection. But, then, the higher the understanding so engacred, the more need there is that it be quite sound; otherwise, it will do the more mischief.

Whether we suppose a sort of flaw, or a certain vicious element in the original mould of a man's mind, something there is which all the world knows and speaks of as a reality. And what the world makes sure of, and is familiar with, it is apt to call by some homely vigorous name; and this it ca!ls wrong.headedness. The name is almost descriptive of the thing itself ; for, wherever it is found, it is always ready to hinder whatever is best within the man from doing its perfect work, and to lcad to perverseness of opinion and conduct.

Now, this (so-called) wrong-headedness is found in various measures, from small to great; but, unfortunately, in practical medicine, a little of it goes a long way; it leavens a large lump. In every profession, business, and calling, with all the advantages of education and special training, men continually fail, from some touch of wrong-headedness in their composition, some trace of defective common sense; and truly that a number of clever, industrious, learned men should meet with notining but bad luck in life is lamentable erough. Still, it would be well for the world if the worst misfortune that could be reckoned were the misfortune of individuals; but the professions, businesses, callings, themselves suffer detriment and discredit and hindrance of advancement at the hands of those who are daily practising them and spoiling them. And, above all, the medical profession; not because there are more wrong-headed men in it than in other pro- fessions, but because a less amount of the fatal ingredient goes to vitiate its conclusions. Medicine has very few scientific tests at its command, and almost all its great questious are left to the sole judgment of well-instructed common sense.

Therefore, we need not be surprised that, taken upou a comparisou with other professions, and having no more than its average proportion with the rest, of that which is naturially antagonistic to common scnse in them all, medicine should sutfer a far greater practical evil frow it.

I have spoken of well-instructed common sense; for common sense has somehow (perhaps from its name) come to be takeu for something coarso in itself and its operations, and ouly fit to be coarsely used. But there is not a thing in the world more delicate, or more casily spoiled, or requiring to be more delicately handled. Left to itself, it is not good for wuch. It must have culture and education; but very different are its issues, according as it is wrongly or rightly educated. It may be sophisticated into folly, or it may be cultivated into sagacity, which is its highest perfection.

Sad tricks have been played with our professional education of late years. Medicine justly claims kindred with all things that are best in human knowledge. But this is not a reason why every mun who is to practise medicine slould be set to learn them all. Let a man learn them all, if he can wield them all ; or as many of them as he can lightly bear and freely use. But a small overweight of knowledge is often a sore impediueut to the movements of com. mon seuse.

If half the scientific things now insisted upon as essentials of medical education were dispensed with to-morrow, the knowledge of them would not perish froin among us. They are much too attractive objects of study not to find many of the best minds always ready to take them up and pursue them zealously and profitably for themselves and their profession; but by those who must learn them they are only half learnt, and serve them for no use whatever, but for a great hindrance.

Should ever a few of the most right-minded and experienced among us set themselves to settle, what is much wanted, a scheme of medical education the fittest and best for all, or for the great majority, and be quite agreed about it, and commend it to the world, it would offend by the fewness of its requircments, and so be unacceptable, and be rejected, and come to nothing; where the hitch and hindrance really lie is plain enough, and ought to be plainly told. Men are vain only about themselves; but about their clan, their calling, their profession, they are more-they are vain-glorious. Hence the extravagant expenditure of all the world upon mere show, socially, morally, mentally. The evil is absolutely incurable; and, alas ! it bears most heavily upon the medical profession, whose basis is common sense.

Common sense is in medicine the master workman. With it a few good solid naterials become the ways and means to practical results infinitely various and important; without it, materials ever so many and ever so good come to nothing or come to mischief.

Moreover, medicine has (so to speak) no one grammar, or orthography, or formal logic of its own. Men may spell it, and write it, and reason it, how they will, and have none to take them to task. It is the result only that is seep or appreciated. 
But, then, the more each man is left to himself, the more strict should he be in his self-questionings; for every man then, being (but in no evil sense) a law to himself, becomes responsible to himself for exact compliance with its requirements, according to his own consciousness of what is right for him. And, might we not add, according to his own conscience, too? For, oftentimes, a man's intellectual self and his moral self must be mutual safeguards and fellow-labourers, if he is to work his way without mischance to the best conclusions. This is preeminately the case in practical medicine.

\section{original Communitations.}

\section{CASES OF BARURIA.}

By C. Haxdfield Joses, M.B., Physician to St. - Mary's Hospital, etc.

CAsE 1. J. G., aged 21, seen Aug. 3rd, 185\%, was of languid, dull, venous aspect. He had had epileptic fits; and his speech and intellect had been disordered since the fits ceased. He could walk well. He died in a state of dementia, greatly emaciated, in December 1859. The post mortem examination showed a healthy state of the encephalon, with the exception of a granular condition of the lining membrane of the ventricles.

His urine on Jan. 26th amounted to 50 ounces in the twenty-four hours; it was of specific gravity 1028, of pretty full colour, and deposited plenty of lithates. Nitric acid caused spontaneous crystallisation of nitrate of urea. He was ordered three minims of nitric acid, seren minims of liquor opii sedativus, and an ounce of infusion of calumba three times a day. This was continued till Feb. 8 th, when tho urine was $25 \$$ ounces in twenty-four hours, of specific gravity 1016 , and clear. The urea at the former date, estimated by Liebig's test, amounted to 641.400 grains; the phosphoric acid amounted to 64.590 grains. At the time of the second examination, the urea had sunk to 239.062 grains; the phosphoric acid to 18.826 grains. Before he began to take the acid and opium, he was losing weight at the rate of one pound per week. On Feb. $8 \mathrm{th}$, he had ceased to lose, but was otherwise unimproved. On Feb. 18th, the daily amount of urine was only 11 ounces, of specific gravity 1025 , clear; and it was almost exactly the same on March 1st. The nitric acid and opium was omitted on Feb. 20th; and carbonate of ammonia, with chloric ether, was given in decoction of Iceland moss. This was continued a long time. On April 27th, the daily amcunt of urine was 10 ounces, of specific gravity 1015; it was clear, and of good colour. The daily amount of urea was now 358.01 grains; of phosphoric acid, 20.570 grains. On Feb. 18 th, the daily amount of urea was 148.5 grains; of phosphoric acid, 11.308 grains. In a tabular form, the daily results stand as follows :-

\begin{tabular}{|c|c|c|c|c|}
\hline & $\begin{array}{l}\text { Quantity. } \\
\text { Ounces. }\end{array}$ & Sp. gr. & $\begin{array}{l}\text { Crea. } \\
\text { Grins. }\end{array}$ & $\begin{array}{l}\text { Phos. acid } \\
\text { Grains. }\end{array}$ \\
\hline In state of baruria & . 50 & 1028 & $6 \pm 1.1$ & 64.50 \\
\hline Under nitric acid $(a)$ & 25.5 & 1016 & 239.062 & 18.126 \\
\hline and opium (b) & 11 & 1025 & 148.5 & 11.308 \\
\hline n normal state. & 40 & 1015 & 358.04 & $20.5 \% 6$ \\
\hline
\end{tabular}

CASE II. Jirs. - aged 40 , the mother of five chil. Aren, was seen July 11th. She complained of increased frequency of micturition, with a sense of burning afterwards, referred to the umbilicus. This chicfly troubled her in the earlier part of the day; not at night, nor in the evening. She was pallid, but in fair health, better than last year, and much less nervous. She was a per. son of calm, sensible mind. The urine was in fair quantity, full-coloured, of specific gravity 1027 ; it depo. sited a flocculent cloud, containing much osalate of limo (octohedra); the crystals were often grouped into small quasi-calculous masses. On adding nitrio acid, effervescence ensued, and some nitrate of urea laminæ were gradually formed (not, however, until the lapse of three or four hours).

Bo Acidi nitrici miij; liquoris opii sedat. $m v$; tincturx lupuli mxx; infusi lupuli $\zeta i$. Fiat haustus ter die sumendus.

July 6th. She was better. The urino was not perccptibly increased in quantity; it was aqueous, pale, of specific gravity 1008 ; there was no sediment, no oxalates, no effervescence with nitric acid; the reaction was. alkaline.

July 19th. She continued much better. She had taken six doses only of the mixture.

The connexion in this instance of resical dysesthesia with barurin, and the remarkable effect of the remedy employed on the urine, can scarcely be questioned.

CASE III. - clerk, aged 25 , of delicate constitution, was seen July 15th, 185t?. He complained of aching uneasiness in loins, which he had had since the previous winter, with great general debility and nervousness. The hypersesthetic state was very evident. His appetite was poor. He was chiefly troubled by a nervous feeling referred to the bladder, leading him to imagine that he wanted to urinate, though he had no real call to do so. If he was at all hurried, he could not urinate at all. 'This vesical dysesthesia he had had for years. The urine was highly acid, of specific gravity 1030 ; it contained an excess of urea, and deposited litlıates and some oxalates.

R Acili nitro-muriat. $m v$; liquoris opii sedat. mix; infusi lupuli $\xi^{i}$. M. Fiat haustus ter dio sumendus.

He continued this treatment till July 28th, when the urine was high coloured, of specific gravity 1027, and deposited no uric acid, nor urates, but octohedra. For the last five days he had also camphor, henbane, and lupulin, twice daily. I then gave him six grains of citrate of jron and quinine three times a day, which was replaced Aug. 1st by strychnia, with a littlo liquor opii sedativus.

Aug. (ith. He reported himself infinitely better. The urine was of normal colour, of specific gravity $10: 21$; the quantity was about the same as before; it deposited no uric acid nor oxalates in twenty-four hours.

The next year be consulted me again, with a return of the same symptoms. Strychnia with citrate of iron und quinine was effectual, with an occasional opium suppository, which very decidedly calmed the resical uneasiness, though it disordered his stomach.

In this instance, strychnia seems to have effected more than the acid and opium. Hyperxsthesia, debility, and baruria were evidently associated together.

Case IV. Mr. V., mid-aged, tall, hollow-eyed, of restless, energetic temperament, has been in India. $\mathrm{He}$ had suffered long with pain in loins, and occasionally had seen blood in his urine. The lumbar pain was such that he found relief from getting a person to sit on him and press his back. His health was very fair in all respects. The urine was of natural colour, of specific gravity 1031, very acid; it contained a trace of albumen, no sugar, no excess of urea (according to the nitric acid test). Nitric acid threw down a sufficiency of lithic acid. There was a large deposit of fine oxalate of lime crystals, octohedra, and dnmbbells.

June 10th. The following medicine was ordered.

$\mathrm{R}$ Acid. nitro-muriat. $m v$; liquor. opii sedat. mvij; infusi lupuli $\zeta$ i. Ml. Fiat haustus ter die sumendus.

Aug. 10th. He reported that he had continued tho medicine ever since, and had benefited greatly. Ho was in better general health than for years; he had not the wearjing pain in the loins, but an occasional acute 